Article

\title{
Predictors of cardiac self-efficacy among patients diagnosed with coronary artery disease in tertiary hospitals in Nepal
}

\author{
Rabina Shrestha, ${ }^{1}$ Lal Rawal, ${ }^{2}$ Rashmita Bajracharya, ${ }^{3}$ Anup Ghimire ${ }^{4}$ \\ ${ }^{1}$ Dhulikhel Hospital Kathmandu University Hospital, Kathmandu, Nepal; ${ }^{2}$ School of Health, Medical and \\ Applied Sciences, Central Queensland University, Sydney Campus, Sydney, Australia ; ${ }^{3}$ University of Maryland, \\ Baltimore, MD, USA; ${ }^{4}$ BP Koirala Institute of Health Sciences, Dharan, Nepal \\ Research carried out in: Manmohan Cardiothoracic and Vascular Transplant Center, Maharajgunj and BP \\ Koiral Institue of Health Science, Dharan, Nepal
}

\begin{abstract}
Background: Cardiac self-efficacy determines how people feel, think, motivate themselves and behave with regards to improving their cardiac health subsequently preventing complications of coronary artery disease (CAD). Given almost one-third of global death is contributed by CAD with $10 \%$ of disability adjusted life years lost in low- and middle-income countries (including Nepal), it is important to identify factors that can promote cardiac self-efficacy. There are no studies in Nepal focusing on predictors of self-efficacy. Therefore, we aim to determine the predictors of cardiac self-efficacy of CAD patients in Nepal.

Design and Methods: This is a cross-sectional study where we recruited 170 patients ( $\geq 30$ years) diagnosed with CAD from two tertiary level hospitals. Multiple linear regression model was used to identify the predictors of cardiac self-efficacy.

Results: The mean age of the participants was $60.45 \pm 10.39$ years (range, 31-83). Most of the participants were diagnosed as myocardial infarction $(91.2 \%)$, rest with unstable angina $(6.5 \%)$ and stable angina $(2.4 \%)$. The multivariate analysis shows age $(p<0.001)$, health behaviors $(p<0.001)$ and knowledge of the disease $(p<0.001)$ were statistically significant predictors to cardiac self-efficacy. Every 1-year increase in age was associated with 0.23 units increase in cardiac self-efficacy score. Similarly, every unit increase in health behavior score and knowledge of disease score was associated with 0.432 units and 0.475 units increase in cardiac self-efficacy score respectively.

Conclusion: Age and health behaviors were the strongest predictors of cardiac self-efficacy followed by knowledge of the disease. We conclude that those with poor health behavior are at a greater risk of poorer cardiac self-efficacy compared to those with relatively good level of self-efficacy. Public health interventions such as awareness raising about cardiac disease and health behavior modification along with early screening, diagnosis and appropriate care are essential to improving self-efficacy and cardiac care outcomes.
\end{abstract}

\section{Introduction}

Cardiovascular diseases are the number one cause of death globally: more people die annually from cardiovascular disease than from any other cause with an estimation of death of 17.9 million people from cardiovascular disease in 2016, representing $31 \%$ of all global deaths out of which $85 \%$ are due to heart attack and stroke. ${ }^{1}$ Coronary artery disease (CAD) is a common term for the buildup of plaque in the heart's arteries that could lead to heart attack. $^{2}$ CAD is a major public health concern because it is the most common type of cardiovascular disease and it accounted for 365,914 deaths in the United States alone in 2017. Moreover, CAD impacts working adult population with twenty percent of deaths associated with CAD contributed by individuals less than 65 years of age. ${ }^{3}$ Like other lower middle income countries (LMICs), Nepal in recent years is witnessing increasing burden of CVDs. ${ }^{4-7}$ In 2016 , CVDs accounted for $28.1 \%$ of total mortality, which was the number one leading cause of death in Nepal.4-7 Compared to increased disease burden, CVDs receive disproportionately less attention and resources in Nepalese health systems. ${ }^{8}$

Perceived self-efficacy is defined as people's perceptions about their potential to perform an activity that influences over events that have an impact on their lives. According to Bandura's definition, individuals' expectations or their belief for success or failure to perform a task will determine their outcome. ${ }^{9}$ In line with this concept of perceived self-efficacy, cardiac self-efficacy is defined as a person's belief in his/her ability to manage the challenges posed by a coronary disease, and its role has been evaluated in several coronary populations using the cardiac self-efficacy scale (CSE Scale). ${ }^{10}$ Cardiac self-efficacy was shown to be the most influencing factor on health behaviors modification. ${ }^{11,12}$ Cardiac self-efficacy can predict key outcomes such as reductions in likelihood of hospital admissions, depression rate in patient, and cardiac functioning following a CAD event. ${ }^{13}$

Cardiac self-efficacy, self-care health behaviors, and modifiable risk factors play an important role to improve quality of life

Significance for public health

The global number of deaths from cardiovascular disease (CVD) has increased during the past decade by 12.5\%. Since the CVD rates are increasing in developing countries including Nepal, a multifaceted approach to prevention and control of CVD is needed. Studies have demonstrated the importance of including selfefficacy as a key component in CVD self-management programs. These programs should be multidisciplinary in approach, should be tailored to the needs of the patients, and should have a theoretical foundation of behavior change. The findings of the study suggest the need for developing public health interventions focused on improving knowledge and behavior for increasing cardiac self-efficacy in patients with coronary artery disease in Nepal. 
(QoL) in adults with coronary artery disease. The modifiable cardiac risk factors are: high blood pressure; high blood cholesterol levels; smoking; diabetes; overweight or obesity; lack of physical activity; unhealthy diet and stress. ${ }^{14}$ In addition to continued follow up care from health care professionals, factors like lifestyle modification and awareness about the disease can prevent individuals from complications and improve quality of life of patients with CAD. But to initiate and keep up with all the changes that CAD brings in the daily routine of the patients, improving their self-efficacy is important. Patients could be more confident in performing self-care health behaviors by more effectively managing their cardiovascular risk factors if interventions are done to improve cardiac self-efficacy. ${ }^{15}$ Past study showed that CAD-specific education and risk-factor awareness were found to be potential predictors of cardiac self-efficacy. ${ }^{12}$ However, it is not clear in the literature if other factors like sociodemographic factors, disease specific factors like comorbidities, duration of illness, BMI, and health behaviors can predict cardiac self-efficacy. Similarly, based on my knowledge there is no study that determined the predictors of cardiac self-efficacy in the adult ( $>20$ years of age) population in Nepal. The predictors identified in this study can help create targeted interventions to improve cardiac self-efficacy among patients with CAD in Nepal. Therefore, the purpose of this study is to determine if sociodemographic factors, disease specific factors like comorbidities, duration of illness, body mass index (BMI), health behaviors can predict cardiac self-efficacy in patients with coronary artery disease in Nepal.

\section{Methods}

\section{Study design}

A cross sectional study was designed for the study.

\section{Settings}

The study was conducted at the Manmohan Cardiothoracic and Vascular Transplant Center, Kathmandu and BP Koirala Institute of Health Science, Dharan, Nepal (data collection: $1^{\text {st }}$ Feb- $28^{\text {th }}$ Feb 2018).

\section{Participants}

A purposive sampling method was used to select the hospitals where patients older than 20 years of age diagnosed as CAD from both hospitals were included. Patients with complications of congestive heart failure were excluded.

Patients diagnosed as CAD were identified through Outpatient Department registration card in the counter and traced in waiting room by the investigator. The diagnosis was confirmed after obtaining their coronary angiogram report. Patient was included as per inclusion/exclusion criteria after taking consent. Equal numbers of patients were enrolled from two centers.

\section{Variables}

\section{Dependent variable}

Cardiac self-efficacy.

\section{Independent variables}

Age, academic qualification, occupation, BMI, smoking (current smoking and former smoking), dietary habit, comorbidity, cardiac knowledge and awareness, patient receiving information about the disease and cardiac health behavior added.

\section{Data source and measurement}

We took a face-to-face interview for a set of structured questionnaires. The tools used have been derived from previously published journals and are well-validated. We divided the questionnaire into 4 sections with demographic data, cardiac awareness and knowledge, cardiac self-efficacy scale and the cardiac health behavior scale. ${ }^{10,16,17}$ All the questionnaires were translated in Nepali and back translated to English. Pretesting of the tool was done by administering the tool to $10 \%$ of the total sample in Patan Heart clinic. The internal consistency (reliability) was measured via Cronbach's alpha, which was found to be 0.78 for cardiac knowledge scale, 0.87 for cardiac self-efficacy scale and 0.757 for cardiac health behavior in our study. This was also well validated when used in other studies as well.

\section{Sample size}

Based on the previous study by Kang et al. ${ }^{12}$ where the mean score for cardiac self-efficacy was 38.78 and SD as 7.38. Using the formula $\left(\mathrm{Z}^{2}(\mathrm{SD})^{2} / \mathrm{L}^{2}\right)$ and considering relative precision $(\mathrm{L})$ as $3 \%$ and absolute precision (1.16\%) and $10 \%$ non-response rate, estimated sample size was 170 patients.

\section{Quantitative variables}

Collected data were entered in Microsoft Excel 2010 by lead author (RS). The entered data were checked after every 50 entries in order to double check any errors in data entry. Data were processed in the form of tabulation and necessary categorization of variables where needed was done. Data security including control, privacy and storage of the data were strictly maintained. Only the researcher and the supervisors had access to the data. The data were then exported to Statistical Package for Social Sciences (SPSS) version 11.5 for statistical analysis.

\section{Statistical analysis}

We calculated frequency and percentage categorical variables and mean and standard deviation (S.D) for continuous variables. Linear regression was used to assess the association of continuous independent variables with the primary outcome for bivariate analysis. Explanatory variables that were significant in bivariate analysis at the level of $<0.2$ were taken for multiple linear regressions analysis. ${ }^{13}$

\section{Results}

This section has been divided into two parts: findings of descriptive statistics (Part A) and inferential statistics (Part B). The descriptive statistics provides the sociodemographic characteristics, disease specific characteristics, health behavior, co morbidities of the patients and the mean score of cardiac self-efficacy, cardiac knowledge and cardiac health behavior. Likewise, the inferential statistics describes the bivariate and multivariate analysis of the cardiac self-efficacy with other variables.

\section{Part A: findings using descriptive statistics}

\section{Sociodemographic characteristics of the participants}

Table 1 shows the socio-demographic characteristics of the participants. The mean age of respondents in the study was 60.45 years with $\mathrm{SD} \pm 10.397$ years, ranging from 31 years to 83 years and equal proportion were found below and above 60 years. Likewise, majority $(80.0 \%)$ of the respondents were male. More than half of the participants $(54.7 \%)$ had attained basic level edu- 
cation while the least (7.1\%) had attained higher education (bachelors and above). Most of the participants (95.3\%) were married, $4.0 \%$ widowed and only $0.6 \%$ was unmarried. Majority $(81.0 \%)$ of the participants did not have any source of income. Most of the participants $(53.4 \%)$ were retired, had no jobs or were housewives and fewer were involved in agriculture $(11.2 \%)$, business $(11.8 \%)$ and services $(11.2 \%)$. More than half of the patients $(57.6 \%)$ were diagnosed for less than 1 year and only $1.2 \%$ were diagnosed for more than 10 years. Half of the respondents (54.1\%) had diabetes and majority $(81.2 \%)$ had hyperlipidemia and more than half of the patients $(58.2 \%)$ were hypertensive.

Asian criteria were used to categorize the BMI of the participants. Equal percentage of respondents fall under normal BMI $(35.9 \%)$ and pre-obese, $21.8 \%$ were overweight, $3.5 \%$ obese and $2.9 \%$ underweight according to Asian criteria (Figure 1). Most of the participants $(91.1 \%)$ were diagnosed as myocardial infarction whereas rests of them were unstable angina followed by stable angina (Figure 2).

\section{Health behavior of the participants}

Majority (91.2\%) of the participants did not smoke at the time of data collection, around half (48.2\%) of the participants were former smoker, and $8.8 \%$ of current smokers. Among current smokers $7.6 \%$ smoked 1 cigarette a day (mild smoker), $0.6 \%$ smoked 4 $\mathrm{cig} /$ day (nicotine dependency), and $0.6 \%$ smoked $7 \mathrm{cig} /$ day (heavy chain smoker).

Regarding the dietary pattern, $77.9 \%$ of the participants used to take green leafy vegetables and fruits 1 to 2 times a day. Regarding the frequency of meat, more than half of the respondents $(65.0 \%)$ had meat intake 1 to 3 times a week and $26.5 \%$ did not take meat at the time of data collection.

The majority $(92.9 \%)$ of the patient had received the information regarding the disease and among them, $97.5 \%$ were satisfied with the obtained information.

\section{Cardiac knowledge, cardiac self-efficacy and cardiac health behavior score}

Table 2 shows the mean score of cardiac knowledge as 17.82 \pm 3.16 , CSE Score as 37.14 \pm 7.32 , and CHB score as $76.01 \pm 6.53$.

\section{Part B: Findings using inferential statistics}

Table 3 shows the result of regression analyses using bivariate analysis of the variables with cardiac self-efficacy. The age of the participants, daily intake of fruits and vegetables, knowledge and health behavior were found to be significant.

Table 4 shows the result of multiple linear regression analysis of the variables with cardiac self-efficacy. The multivariate analysis found age $(\mathrm{p}<0.001 ; 95 \% \mathrm{CI}:-0.32$ to -0.14$)$, health behaviors $(p<0.001 ; 95 \%$ CI: 0.29 to 0.57$)$ and knowledge of the disease ( $\mathrm{p}<0.001 ; 95 \%$ CI: 0.19 to 0.75 ) as statistically significant predictors of cardiac self-efficacy. Every 1-year increase in age was associated with 0.23 units increase in cardiac self-efficacy score.
Similarly, every unit increase in health behavior score and knowledge of disease score was associated with 0.432 units and 0.475 units increase in cardiac self-efficacy score respectively.

\section{Discussion}

The findings of this study provide predictors of cardiac selfefficacy among the patients with diagnosed coronary disease in Nepal. The findings from bivariate analysis showed that age, daily intake of fruits and vegetables, cardiac health behavior, and cardiac knowledge were associated with cardiac self-efficacy. The findings

Table 1. Socio-demographic characteristics of the respondent $(\mathbf{n}=\mathbf{1 7 0})$.

\begin{tabular}{|c|c|c|}
\hline Characteristics & $\begin{array}{l}\text { Frequency } \\
(\mathrm{n}=170)\end{array}$ & $\begin{array}{c}\text { Percent } \\
(\%)\end{array}$ \\
\hline $\begin{array}{l}\text { Age (in years) } \\
\text { Less than } 60 \\
\text { Above } 60\end{array}$ & $\begin{array}{l}85 \\
85\end{array}$ & $\begin{array}{l}50.0 \\
50.0\end{array}$ \\
\hline Mean age \pm S.D (years) & $60.45 \pm 10.397$ & \\
\hline $\begin{array}{l}\text { Gender } \\
\text { Male } \\
\text { Female }\end{array}$ & $\begin{array}{l}136 \\
34\end{array}$ & $\begin{array}{l}80.0 \\
20.0\end{array}$ \\
\hline $\begin{array}{l}\text { Ethnicity } \\
\text { Dalit } \\
\text { Disadvantage Janjati } \\
\text { Disadvantatenon Dalit Terai caste group } \\
\text { Religious minorities } \\
\text { Relatively advantaged Jantaji } \\
\text { Upper ethnic group }\end{array}$ & $\begin{array}{c}6 \\
23 \\
25 \\
6 \\
29 \\
91\end{array}$ & $\begin{array}{c}3.5 \\
13.5 \\
8.8 \\
3.5 \\
17.1 \\
53.6\end{array}$ \\
\hline $\begin{array}{l}\text { Academic status } \\
\text { Illiterate } \\
\text { Basic level } \\
\text { Secondary level } \\
\text { Bachelors \& above }\end{array}$ & $\begin{array}{l}31 \\
93 \\
34 \\
12\end{array}$ & $\begin{array}{c}18.2 \\
54.7 \\
20.0 \\
7.1\end{array}$ \\
\hline $\begin{array}{l}\text { Marital Status } \\
\text { Unmarried } \\
\text { Married } \\
\text { Widowed }\end{array}$ & $\begin{array}{c}1 \\
162 \\
7\end{array}$ & $\begin{array}{c}0.6 \\
95.3 \\
4.1\end{array}$ \\
\hline $\begin{array}{l}\text { Occupation } \\
\text { Agriculture } \\
\text { Business } \\
\text { Service } \\
\text { Housewife } \\
\text { Other }\end{array}$ & $\begin{array}{l}19 \\
20 \\
19 \\
21 \\
91\end{array}$ & $\begin{array}{l}11.2 \\
11.8 \\
11.2 \\
12.4 \\
53.4\end{array}$ \\
\hline $\begin{array}{l}\text { Comorbidity } \\
\text { Hyperlipidemia } \\
\text { Diabetes } \\
\text { Hypertension } \\
\text { Others }\end{array}$ & $\begin{array}{l}138 \\
92 \\
99 \\
24\end{array}$ & $\begin{array}{l}81.2 \\
54.1 \\
58.2 \\
14.2\end{array}$ \\
\hline
\end{tabular}

Table 2. Cardiac knowledge, cardiac self-efficacy and cardiac health behavior score $(n=170)$.

\begin{tabular}{lcccc} 
Variables & No. of items & Minimum & Maximum \\
Knowledge score & 26 & 8 & 25 & $17.82 \pm 3.18$ \\
CSE score & 13 & 16 & 52 & $37.14 \pm 7.32$ \\
\hline CHB score & 22 & 53 & $76.01 \pm 6.53$ \\
\hline
\end{tabular}


from the multivariate analysis revealed age of the participants, cardiac health behavior and cardiac knowledge to be the predictors for cardiac self-efficacy.

Consistent with findings from the past study, increasing age was associated with a decreased cardiac self-efficacy. ${ }^{18}$ With the increase in age, the self-efficacy of the person decreases. Comparison of the performance of self-care/recovery behaviors with other samples from the literature found recovery in the elderly to be protracted. ${ }^{19}$

Similar to the findings from the past studies, improved cardiac health behavior was associated with an increased cardiac self-efficacy. ${ }^{20,21}$ The evidence shows self-efficacy, self-care health behaviors, and modifiable risk factors play an important role in quality of life in adults with coronary artery disease. ${ }^{15}$ These findings are also consistent with the findings presented by other studies which were conducted among CAD patients in Seoul, Korea, Australia and San Francisco. ${ }^{12,22,23}$ A study in Iran, Tehran Heart Center also concluded that the cardiac self-efficacy had a positive and significant relationship $(p<0.001)$ with functional status. ${ }^{24}$ The findings were also congruent with a study conducted in Aceh Province, Indonesia where self-efficacy was significantly and positively correlated with CAD preventive behaviors. ${ }^{25}$

Similar to the past findings, increase in cardiac knowledge was

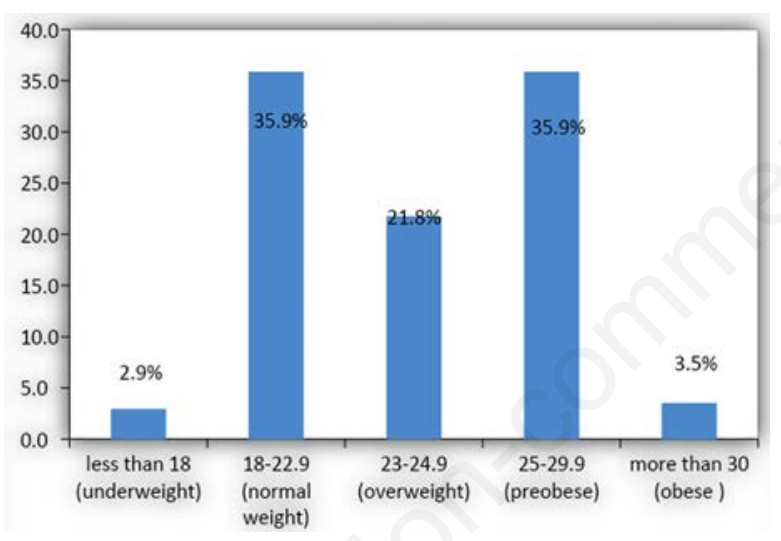

Figure 1. Disease specific characteristics of the respondents; body mass index of respondents $(n=170)$.

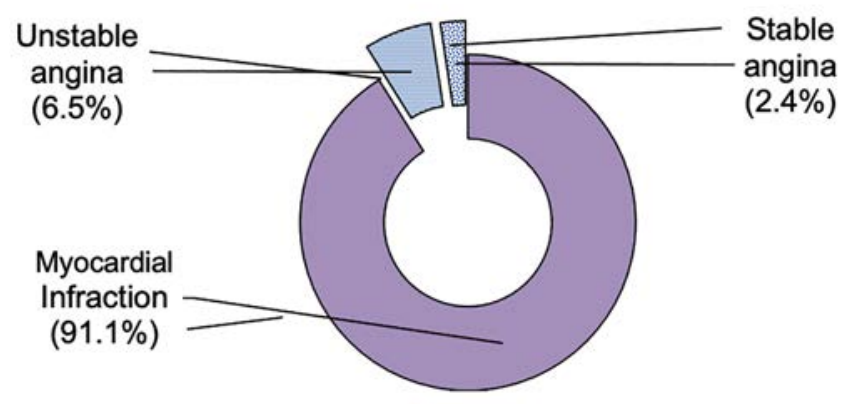

Figure 2. Distribution of respondents according to the type of coronary artery disease $(n=170)$. associated with an increase in cardiac self-efficacy. ${ }^{20,21}$ There is evidence of lower levels of self-efficacy and poorer patient-physician interactions predicting poor health-related quality of life (HRQoL) which concluded that health providers should be aware of these factors in coronary heart disease (CHD) patients when trying to improve their QoL. ${ }^{22}$ Likewise in a study done in cardiology unit and $\mathrm{CCU}$, after implementation of the educational guidelines, highly statistically significant improvement regarding the total post and follow up test satisfactory scores of knowledge, cardiac self-efficacy, and cardiac exercise self-efficacy, somatic health complaints and anxiety level for the study group subjects was found. ${ }^{26}$

Table 3. Bivariate analysis of variables with the cardiac self-efficacy.

\begin{tabular}{lccc}
\hline Variables & \multicolumn{3}{c}{ Bivariate analysis } \\
& $\beta$ & SE & p-value \\
Age & -0.21 & 0.052 & $<0.001^{*}$ \\
Gender & -1.35 & 1.40 & 0.33 \\
\hline Marital status & 0.02 & 2.634 & 0.99 \\
Ethnicity & 0.315 & 0.345 & 0.36 \\
\hline Income & -2.84 & 0.507 & 0.57 \\
Occupation & -0.203 & 0.389 & 0.60 \\
\hline Diagnosis & 2.334 & 1.463 & 0.11 \\
Period since diagnosed & 0.898 & 0.416 & 0.32 \\
\hline BMI & 1.79 & 1.029 & 0.08 \\
Current smoking status & 3.81 & 1.96 & 0.05 \\
\hline Former smoking status & -9.05 & 1.12 & 0.42 \\
Daily intake of fruits and vegetables & 3.33 & 1.31 & $0.01 *$ \\
\hline Intake of meat & 1.16 & 1.00 & 0.24 \\
Presence of diabetes mellitus & 0.61 & 1.13 & 0.58 \\
\hline Presence of hyperlipidemia & 2.32 & 1.43 & 0.10 \\
Presence of comorbidity & 1.48 & 1.25 & 0.24 \\
\hline Patient education status & -3.91 & 2.18 & 0.07 \\
Patient satisfaction status on education & 0.08 & 3.68 & 0.98 \\
\hline Knowledge score & 0.797 & 0.166 & $<0.000^{*}$ \\
Health behavior score & 0.539 & 0.076 & $<0.000^{*}$ \\
\hline *Significant at the level of <0.2. & & & \\
\hline
\end{tabular}

Table 4. Multivariate analysis of the variables with cardiac self-efficacy.

\begin{tabular}{lccc}
\hline Variables & \multicolumn{3}{c}{ Bivariate analysis } \\
Age of participant in years & -0.230 & 0.044 & $0.000^{*}$ \\
Diagnosis & 1.527 & 1.167 & 0.193 \\
\hline Period since diagnosed & 0.680 & 0.341 & $0.048^{*}$ \\
BMI of participants & 0.394 & 0.833 & 0.637 \\
\hline Daily intake of fruit and vegetables & 2.079 & 1.064 & 0.052 \\
Presence of hyperlipidemia & 3.010 & 1.159 & $0.010^{*}$ \\
\hline Status of patient education & -1.795 & 1.736 & 0.303 \\
Cardiac knowledge & 0.475 & 0.145 & $0.001^{*}$ \\
\hline Cardiac health behavior & 0.432 & 0.072 & $0.000^{*}$ \\
\hline *Significant at the level of $<0.2$. & & &
\end{tabular}




\section{Conclusion}

We conclude that the age and health behaviors were the strongest predictors of cardiac self-efficacy among the patients with coronary artery diseases in Nepal, followed by knowledge of the disease. These findings suggest that those with poor health behavior are at a greater risk of poorer cardiac self-efficacy which has greater impact on overall poor health outcomes. Therefore, there is a need for developing intervention approaches, in particularly raising cardiac health awareness and improving healthy behavior are essential to improve self-efficacy and overall health outcomes.

\section{Study limitations and recommendations}

Since this study included only two centers of Nepal, it might not represent the whole Nepal. Therefore, a larger sample is recommended for understanding the predictors of cardiac self-efficacy in future study. Further, from the findings of the study, we can recommend that intervention dedicated towards improving knowledge of the patients about cardiac health, specifically targeting those with poor health behavior could improve the cardiac selfefficacy of the patients.

Correspondence: Rabina Shrestha, Dhulikhel Hospital Kathmandu University Hospital, Kathmandu, Nepal.

Tel. +977.9841075460 / +977.9801003182.

E-mail: rabinasresta@kusms.edu.np

Key words: Cardiac self-efficacy; coronary artery disease; knowledge; health behavior.

Contributions: RS, concept formation, manuscript writing, editing and submission; LBR, manuscript editing and proofread, final review and expert opinion; RB, manuscript editing and proofread; AG, main guide during the thesis, helped in concept formation and plan for data collection. All the authors have read and approved the final version of the manuscript and agreed to be accountable for all aspects of the work.

Conflict of interest: The authors declare that they have no competing interests, and all authors confirm accuracy.

Ethics approval and consent to participate: All procedures performed in studies involving human participants were in accordance with the ethical standards of the Institutional Research Committee and with the 1964 Helsinki declaration and its latest amendment. Patient was included as per inclusion/exclusion criteria after obtaining consent.

Availability of data and materials: The data used to support the findings of this study are available from the corresponding author on reasonable request.

Patient consent for publication: Not applicable.

Received for publication: 15 May 2020.

Accepted for publication: 29 November 2020 .

oCopyright: the Author(s), 2020

Licensee PAGEPress, Italy

Journal of Public Health Research 2020;9:1787

doi:10.4081/jphr.2020.1787

This work is licensed under a Creative Commons Attribution NonCommercial 4.0 License (CC BY-NC 4.0).

\section{References}

1. WHO. Cardiovascular Diseases 2020. Available from: https://www.who.int/health-topics/cardiovasculardiseases/\#tab=tab_1

2. American Heart Association. Coronary Artery Disease Coronary Heart Disease Jul 31, 2015. Available from: https://www.heart.org/en/health-topics/consumerhealthcare/what-is-cardiovascular-disease/coronary-arterydisease

3. Centers for Disease Control and Prevention (CDC) [Internet]. Heart disease facts. Updated 8/9/2020. Available from: https://www.cdc.gov/heartdisease/facts.htm\#: :text=Coronary \%20Artery\%20Disease,killing\%20365\%2C914\%20people $\% 2$ 0in $\% 202017$.\&text $=$ About $\% 2018.2 \% 20$ million $\% 20$ adults $\% 2$ 0age,have $\% 20$ CAD $\% 20$ (about $\% 206.7 \% 25$ ).\&text=About $\% 20$ 2\%20in\%2010\%20deaths,less\%20than \%2065\%20years\%20ol d

4. Dhungana RR, Pandey AR, Bista B, Joshi S, Devkota S. Prevalence and associated factors of hypertension: A community-based cross-sectional study in municipalities of Kathmandu, Nepal. Int J Hypertens 2016;2016:1656938.

5. Rawal LB, Kanda K, Mahumud RA, et al. Prevalence of underweight, overweight and obesity and their associated risk factors in Nepalese adults: Data from a Nationwide Survey, 2016. PLoS One 2018;13:e0205912.

6. Dhitali SM, Karkiii A. Dealing with the burden of hypertension in Nepal: current status, challenges and health system issues. Regional Health Forum; 2013.

7. Dhimal M, Karki KB, Sharma SK, et al. Prevalence of selected chronic non-communicable diseases in Nepal. J Nepal Health Res Counc 2019;17:394-401.

8. Gautam R. NCDs in Nepal: Burgeoning Burden amid low priority and the ways forward. Health Prospect: J Public Health 2013;11:4-5.

9. Bandura A. Self Efficacy. In: Ramachaudran VS, editor. Encyclopedia of Human behavior: New York: Academic Press; 1994. p. 71-81.

10. Fors A, Ulin K, Cliffordson C, et al. The cardiac self-efficacy scale, a useful tool with potential to evaluate person-centred care. Eur J Cardiovasc Nurs 2014;14:536-43.

11. Kang Y, Yang IS, Kim N. Correlates of health behaviors in patients with coronary artery disease. Asian Nurs Res (Korean Soc Nurs Sci) 2010;4:45-55.

12. Kang Y, Yang I-S. Cardiac self-efficacy and its predictors in patients with coronary artery diseases. J Clin Nurs 2013;22:2465-73.

13. O'Neil A, Berk M, Davis J, Stafford L. Cardiac-self efficacy predicts adverse outcomes in coronary artery disease (CAD) patients. Health 2013;05:6-14.

14. Hajar R. Risk factors for coronary artery disease: Historical perspectives. Heart Views 2017;18:109-14.

15. Ahn S, Song R, Choi SW. Effects of self-care health behaviors on quality of life mediated by cardiovascular risk factors among individuals with coronary artery disease: A structural equation modeling approach. Asian Nurs Res 2016;10:158-63.

16. Song R, Oh H, Ahn S, Moorhead S. Validation of the cardiac health behavior scale for Korean adults with cardiovascular risks or diseases. Appl Nurs Res 2018;39:252-8.

17. Kayaniyil S, Ardern CI, Winstanley J, et al. Degree and correlates of cardiac knowledge and awareness among cardiac inpatients. Patient Educ Couns 2009;75:99-107.

18. Salari A, Rouhi Balasi L, Moaddab F, et al. Patients' cardiac self-efficacy after coronary artery angioplasty. Jundishapur J 
Chronic Dis Care 2016;5:e60308.

19. Carroll DL. The importance of self-efficacy expectations in elderly patients recovering from coronary artery bypass surgery. Heart Lung 1995;24:50-9.

20. Yehle KS, Plake KS. Self-efficacy and educational interventions in heart failure: a review of the literature. J Cardiovasc Nurs 2010;25:175-88.

21. Polsook R, Aungsuroch Y. A cross-sectional study of factors predicting readmission in Thais with coronary artery disease. $\mathrm{J}$ Res Nurs 2020. doi: 10.1177/1744987120946792.

22. Barham A, Ibraheem R, Zyoud SeH. Cardiac self-efficacy and quality of life in patients with coronary heart disease: a crosssectional study from Palestine. BMC Cardiovasc Dis 2019;19:290.
23. Sarkar U, Ali S, Whooley MA. Self-efficacy and health status in patients with coronary heart disease: findings from the heart and soul study. Psychosom Med 2007;69:306-12.

24. Allahverdipour H, Asgharijafarabadi M, Heshmati R, Hashemiparast M. Functional status, anxiety, cardiac self-efficacy, and health beliefs of patients with coronary heart disease. Health Promot Perspect 2013;3:217-29.

25. Idyan Z, Thato R. Determinants of Preventive behaviors for coronary artery disease among adults in Aceh Province, Indonesia. J Health Res 2017;31:109-17.

26. Ebraheim MN, Khorais AM. Effect of educational guidelines on cardiac self efficacy, health complaints and anxiety level among patients with coronary artery disease. Egypt J Health Care 2016;7:406-31. 